\title{
A Contrastive Study of Stancetaking in Obama's Political Discourse
}

\author{
Conchi Hernández-Guerra \\ Universidad de Las Palmas de Gran Canaria \\ conchi.hernandez@ulpgc.es
}

\begin{abstract}
An analysis of stancetaking in discourses enables us to analyze the implicit attitude of the speaker in a message. Although this is interesting in itself when dealing with general texts, it is even more important when dealing with political discourse. As it is well-known, President Barack Obama is known as one of the best orators and many studies corroborate this. The aim of this paper is to analyze three different speeches by Obama over a period of two years, delivered in three different countries, to analyze the differences in the stances used in order to determine his implication in the message. Secondly, I shall apply the Chi-square statistical method (X2) to compare the expected frequency of using stance markers with the stated frequency to reveal the possible incongruences.
\end{abstract}

Keywords: stancetaking, political discourse, epistemic approach

\section{Introduction}

The aim of the paper is twofold: on the one hand, I want to make a contrastive study between the three texts analyzed in order to determine the frequency level of the different stances, both epistemic and effective, in them. In this way, I can interpret Obama's attitude in each venue, regardless of the message or expressions used. The second aim is to compare the epistemic and effective stances in each text following the Chi-square statistical model to reveal the common aspects.

This research is based on the theoretical framework where epistemic and effective stances are described in discourses. Stance has been defined as all those expressions 
that reveal "personal feelings, attitudes, value judgments, or assessments" (Biber et al., 1999: 966). This field is always revealing to the extent that subliminal messages can be appreciated. To cite only one example, some authors analyze those stances in different languages (Durant, 1990; Cavanaugh, 2012) to reveal the syntactic mechanisms that reflect those elements. Zupnik (1994) focuses her analysis on the personal pronoun as a deictical element in political discourse. Gastil (1992) makes an analysis of political discourse from a syntactic viewpoint. He includes rhetorical strategies and conversational tactics from a theoretical perspective.

This stated, the scope of our analysis looks original insofar the speeches by President Obama are the object. Indeed, what I am trying to do is expose whether the use of stance markers in his speeches provides some revealing information. That is, whether his attitude and personal implication varies depending on the venue. To do this, I shall base the study on Biber et al.'s proposal of stances with Marín-Arrese's improvements. The reason is that they consider as a starting point that any political speech contains a personal role, cultural component and intentionality. The distinction between epistemic and deontic offered by them identifies the position of the speaker and the expression of the events themselves, key concepts in the corpus of this study.

Biber et al. considered four different types but offered no subdivisions. Nevertheless, Marín-Arrese chose the two most relevant of Biber's types and widened them into different sub-types. In her study she is comparing two different British politicians talking with reference to the very same topics, so every subtle element of distinction is relevant. Also, Alonso-Almeida proposed this model for his study on seventeenth century prefaces on obstetrics, as we shall see later.

The structure of the paper is as follows: first, I shall offer a theoretical frame of stancetaking. In this, I shall explain the different stance features and Marín-Arrese's model will be described. Secondly, the corpus and method will be illustrated. Finally, results and discussion of findings will be presented.

\section{Theoretical frame}

The term "stance" refers to the expressions, registers and elements that reflect the attitude of the speaker towards the message he/she is transmitting. Although this concept may seem somewhat recent, the same idea was widely used some decades ago as "mood" by Jakobson. For him, mood signals the speaker's view of the action being referred to (see Kockelman, 2004). Lately, the analysis of stance markers in texts has had different considerations according to the type of texts analyzed. So, Biber et al. (2000) state that we must consider not only syntactic but also paralinguistic devices. The first type is easy to recognize though not the second in which affective and evaluative word choice are included. Trying to classify this, Biber et al. distinguish between epistemic stance to mark certainty, actuality, precision or limitation, and attitudinal stance to report personal attitudes and feelings. 
Being abstract concepts as they are, researchers do not agree completely in the scope of every term. Kockelman prefers to distinguish between epistemic and deontic categories while recognizing that "even when divisions used by linguists break with the deontic versus epistemic distinction, they turn to another widely used and analogous distinction: affective versus epistemic" (2004: 130). For him, deontic stancetaking is used to refer to the speaker's mood or feeling.

Other writers like Alonso-Almeida et al. (2014) and Marín-Arrese (2009) prefer to distinguish between effective and epistemic stance. Alonso-Almeida did research under this umbrella on seventeenth century prefaces on obstetrics and Marín-Arrese on some British political speeches. The latter also studied the differing degrees of subjectivity and intersubjectivity in these speeches. For both authors, effective strategies are related to the notions of necessity and obligation and Biber et al.'s attitudinal stances are included as a subgroup, so they widen the scope of possibilities. To sum up, attitudinal, deontic and effective are the names for three categories with some elements in common but with slight differences for the different authors.

The proposal offered by Marín-Arrese (2009) was influenced by Langacker's distinction between effective and epistemic stance (2007). Plainly speaking, she considers that the effective level "pertains to the actual occurrence of events" (MarínArrese, 2009: 27; Langacker, 2007: 6), whereas the epistemic level concerns "our presumed knowledge of these events" (Marín-Arrese, 2009: 27; Langacker, 2007: 6). Put differently, she considers the attitudinal stance, in which effective stancetaking would be included, to be the one that reports personal attitudes or feelings, whereas the epistemic stance presents "speakers' comments on the status of information in a proposition" (Biber et al., 2000: 972).

Added to this, Biber et al. (2000) organizes the different syntactic devices that can be included into stance adverbials (single adverbs, hedges, prepositional phrases, adverbial clauses and comment clauses), complement clauses (controlled by a verb, by an adjective, extraposed structures and controlled by a noun), modals and semi-modals, stance noun plus a prepositional phrase (the case of "deny the possibility of..."), and premodifying stance adverbs (the case of "I am so happy for you. I'm really happy"). Next, I shall offer a brief overview of the different categories with their sub-categories.

\subsection{Epistemic stances}

Epistemic stances refer to the knowledge that the speaker has of the realization of the event and also of the validity that the speaker gives to that proposition designating the event. So, it has not only to do with the assertion of an event but also with the evaluation given to that event.

These stances are rather objective as they refer to real and tested events. In a way, it indicates the personal attitude of a speaker. For the analysis of this domain, researchers have offered several strategies: epistemic modality, communicative evidentials, experiential evidentials and cognitive evidentials. 
Epistemic modality reflects the degree of certainty or uncertainty the speaker shows in an assertion. Here, modal verbs are the syntactic elements that reflect this sort of stance. At the same time, there can be three different degrees: when there is a high degree of certainty, the modal verbs "must" and "cannot" are some examples; when there is a medium probability according to the writer, "will", "would" or "shall" could be some examples; and when there is a low possibility, "may" or "could" can be considered. The use of sentences with a low possibility of occurrence should not be very common.

Secondly, communicative evidentials cover those expressions that make a selfreference in the message. As a consequence, the speaker reveals his/her implication in the message. An example could be "as I said". Experiential evidentials, on the contrary, reflect the way the speaker receives the message, how the information is gained through senses. The role is passive as he/ she is just a witness of the information offered. Some examples would be "I see" and "clearly". Finally, cognitive evidentials include those cognitive verbs representing modes of knowing. Some examples would be "I believe" or "we consider".

\subsection{Effective or attitudinal stances}

They deal with the realization of the facts themselves or how we deliver them. As we see, these are extraordinarily interesting to the extent that they reveal those attitudinal differences of the same subject. The division is the following: deontic modality, volitive modality, participant internal and external possibility, participant internal and external necessity, attitudinal expressions, communicative evidentials and imperative mood.

Deontic modality is mainly performative and the context influences greatly. Yet, roughly speaking, "may" and "can" are the appropriate modals to give possibility, permission or, in some examples, command; "must" would be the modal to state necessity and is said to urge or impose an obligation on oneself, as would be the case of "I must say". Volitive modality reveals the ways of expressing the future and the intention in the event realization. "Will" and "shall" are the most common modals. Next, participant internal and external possibility reflects the ability of the speaker to carry out the event designated, considering the external circumstances. A clear example of this in our author's speeches is his famous sentence "Yes, we can". On the other hand, participant internal and external necessity is fairly similar to the previous category but focused on the urgency in the development of an event. "Need" is the clearest example.

Attitudinal expressions are the fifth subgroup and the range of possibilities is reasonably large. In it the speaker reflects his interest that something will happen, regardless the options of success. "I want" is the most commonly used, and others like "it is important" or "hopefully" are also examples in this subclass. To end with, communicative evidentials comprise all those performative verbs such as "I say to you" or "I urge you to" and, finally, the imperative mood typically functions to give directives. In this sort of text, "let" is often used and any imperative verb. 


\section{Corpus and Method}

I shall base the study on three different speeches by President Barack Obama in the years 2008 and 2009. The relevance of these speeches lies in the fact that they were delivered in three different countries (Ghana, France and the USA) belonging to three different continents with different purposes: on the one hand, in Ghana he offered economic support as long as the country avoids corruption; in the second example, he needed European support for the Iraqi war; and in the third speech, he had to defend the man who had been his religious leader for years against the criticism of him for his polemical words.

As we might guess, not only the purpose but also the connotations of the speech are important: in Ghana we find relevant affective connotations for the blood ties; in France his position is difficult as he is demanding economic and logistic support for the uncomfortable task of supporting a war; and in the USA we are dealing with his famous speech on race where he talks about something as controversial as being black in America.

\subsection{The speech in Europe}

The purpose of this trip was to persuade the Europeans of the need to increase the number of troops and resources to solve the military conflict in Afghanistan in 2009. Two concepts are central in this text: crossroads and boundaries. He uses crossroads as a concept that describes Strasbourg (where the speech was delivered) geographically and as a consequence of living in an increasingly connected world. Secondly, this speech is based on the need for boundaries between Europe and America in order to achieve important global results. He offers an overview of the events that have linked both continents since the Marshall Plan and the need to continue with these ties. After that, he refers to the purpose for this visit: to renew the partnership between America and Europe, to explore the reasons why they are fighting in Afghanistan and, thirdly, to ask for more support. He finishes with a hopeful note.

Taken as a whole, this does not fit the register we are used to so the speech can be considered as an untypical. Traditionally, President Obama's speeches are positive and give hope even in hard times. In this case, however, he focuses on terror and threats. The tone is pessimistic and the main purpose is to discuss the problems of globalization and the reasons why the USA and NATO have attacked Afghanistan.

Obama uses plain English with blunt messages to approach the young audience. As a consequence, he is more concerned with the message than the structures used so grammar is simple and repetitive. Despite the pessimistic tone, negative adjectives are not frequent. Moreover, positive words and the need for collaboration open the speech and a hopeful message closes it. Added to this, every threat made in the body of the message is mixed with references to the countless times the United States has offered help to Europe (Hernández-Guerra, 2012). 


\subsection{The speech in the United States}

The model will be applied to a speech delivered on March 18, 2008 by Barack Obama at the Constitution Center in Pennsylvania, Philadelphia. In it, Obama responds to the criticism of Reverend Jeremiah Wright, an unpaid campaign adviser and pastor at Obama's Chicago church. Wright had made inflammatory remarks in matters of war and racism in the States and Obama uses this as an opportunity to challenge Americans to take a closer look at race relations.

The thread of Obama's speech is the unity of all Americans: black, white and Hispanic. He starts and finishes with a reference to the American Declaration of Independence. The speech is well-constructed and balanced between what he agrees with and what he disapproves of, inserting some well-known American quotations and references to the Bible. He speaks openly with reference to race as an African-American with a white mother and deals cleverly with both sides of the race question.

Obama was at a crucial moment in his campaign because of the difficulty in the task he faced with this speech, as not only had he to explain why Reverend Wright had been his spiritual leader for so long, but also justify some declarations he disagreed with. At the same time, he was aware that he could not afford to disappoint the African American community. To do all this, it was absolutely necessary to be straightforward in his message and avoid any misunderstanding that could extend the debate. The final result is a clear and balanced message.

This text has some characteristics of written discourse in the effective linkage of the different angles the topic contains. The message has been carefully organized and the well-chosen quotations are also denotative of a prepared text. At the same time, Obama has tried to create a colloquial mood by using common expressions. He has avoided complex structures and sophisticated vocabulary in order to reach people. Plain language is seen not only in the limited use of adjectives but in the frequent use of the verb "to be" and simple tenses.

Finally, "offbeat" is the word that best defines the structure of the text to denote the complexities of the society Americans live in. Historical contrasts between blacks and whites in Obama's own family and between Reverend Wright's words and his own opinion of the matter are the axis of the speech. (Hernández-Guerra, 2011).

\subsection{The speech in Ghana}

The third speech was delivered in the town of Accra in Ghana in 2009, the same year that Barack Obama was elected President of the United States. This speech encompasses the following parts: firstly, President Obama opens the dissertation by explaining the reason for his visit to Ghana. The tone is positive and hopeful. He remarks on the mutual responsibility that both countries have in the progress of Africans. This encouraging presentation is reinforced with personal reference to his own family in Africa. The second part of the speech covers the present reality: the unfulfilled promises and the responsibility that the country itself has to solve its own 
problems: Obama condemns corruption but offers hope to youngsters. After that, he expresses the four issues he will deal with in the speech: democracy, opportunity, health, and the resolution of conflicts. In all of them he discusses the current problems exemplified in other African countries. To the second and third predicaments he offers economic solutions and to the fourth, a promise. He ends with a hopeful and encouraging message and a quote from Martin Luther King in a visit to the country.

After a comprehensive analysis of the text we recognize that Obama has created a close network between the messages he wants to transmit and a conciliatory atmosphere. The affective bundle of boundaries, links, common knowledge of the country and understanding is more straightforward than the stylistic devices he exploits.

This interconnection is reflected, firstly, in the ties so often repeated in the initial paragraphs and translated into connections in the following. Undoubtedly, his roots are used not so much as a tool to show his understanding and knowledge of the country but as a means to show his determination to fulfill the agreed commitments.

Secondly, the high frequency of references to Africa opens the message. The use of informal language and simple structures creates a colloquial environment where the first person singular pronoun is noticeable. The use of simple present also reflects the degree of improvisation in the text. The orator feels self-confident enough to speak to an audience whose past and present he knows well. It is this knowledge what allows him to have these literary conventions throughout the text. Lastly, criticisms are always in opposition to praises. References to problems are always followed by an appreciation of achievements.

To carry out the first aim of this paper, texts were analyzed and examined manually. This process was done carefully as three readings were carried out. The examples found were tagged according to the main stance types and sub-types to be analyzed. For the second aim the concluding data were then analyzed from a statistical perspective. To do this I have used the Chi Square method $\left(\mathrm{X}^{2}\right)$. With Chi Square, a value is calculated from the data using Chi Square procedures and then compared to a critical value from a Chi Square table with degrees of freedom corresponding to that of the data. If the calculated value is equal to or greater than the critical value, the null hypothesis (Ho) is rejected. If the calculated value is less than the critical value, the null hypothesis is accepted. The advantage of using this is that it can be employed to test the difference between an actual sample and another hypothetical or previously established distribution such as that which may be expected due to chance or probability. Chi Square has also been used to test differences between the different samples (Key, 1997).

Fig. 1. Chi square formula

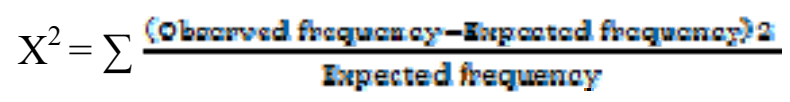




\section{Results and Discussion}

The general results of the study of the corpus concerning epistemic and effective stance with frequencies per 1,000 words are expressed in Figure 2:

Fig.2. Epistemic and effective stances in the speeches (frequencies to 1,000 words)

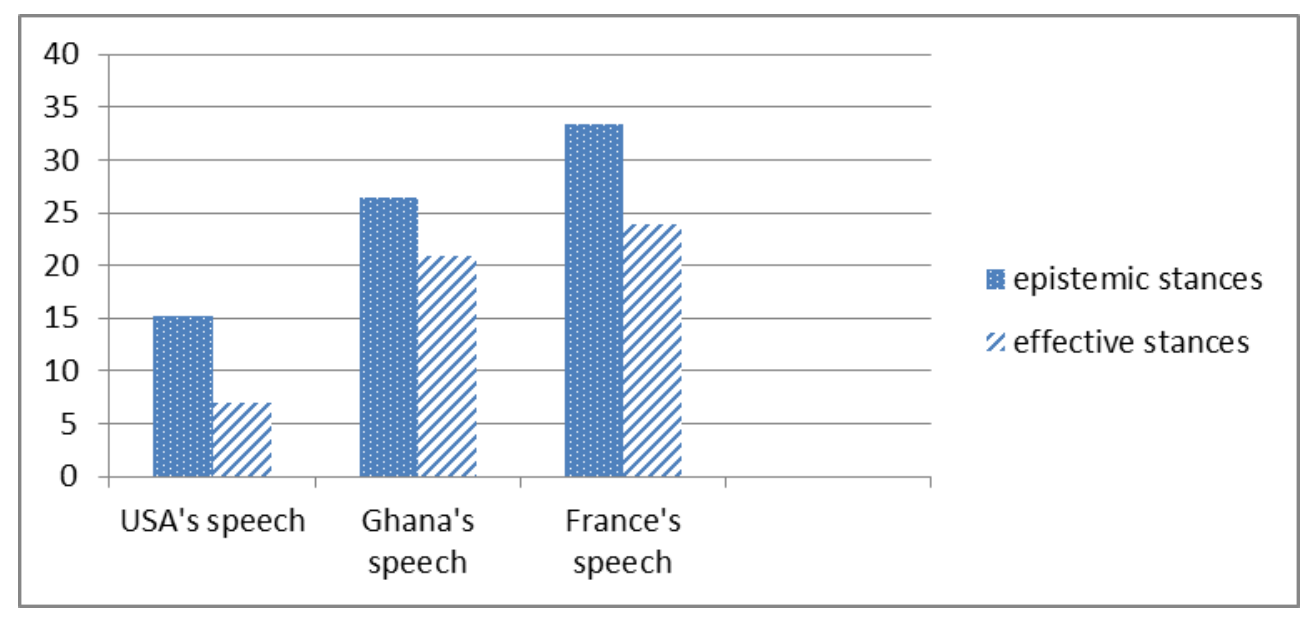

In raw numbers, we can see how speeches delivered in foreign countries (Ghana and France) are largely similar as far as stancetaking is concerned, while the speech on race, delivered in the States, contains fewer examples. Even more remarkable is the limited number of effective stances in this last speech.

If we analyze the different stance markers and give the frequency of occurrence per 1,000 words, the result will be the following:

Table 1. Distribution of epistemic and effective stance strategies per 1,000 words in the corpus

\begin{tabular}{|c|c|c|c|}
\hline Epistemic stances & USA & Ghana & France \\
\hline \multicolumn{4}{|l|}{ Epistemic modality } \\
\hline High & 3.86 & 9.13 & 13.40 \\
\hline Medium & 2.84 & 7.10 & 4.44 \\
\hline Low & 0.81 & 0 & 0.89 \\
\hline Communicative evidentials & 1.01 & 1.52 & 0.29 \\
\hline Experiential evidentials & 3.66 & 6.34 & 6.25 \\
\hline Cognitive evidentials & 3.05 & 2.28 & 8.04 \\
\hline Effective stances & USA & Ghana & France \\
\hline Deontic modality & 1.01 & 4.06 & 7.74 \\
\hline Volitive modality & 1.42 & 6.59 & 2.97 \\
\hline Part. Int. Ext. possibility & 2.44 & 6.59 & 8.93 \\
\hline Part. Int. Ext. necessity & 1.01 & 0.50 & 0.29 \\
\hline Attitudinal experience & 0.20 & 2.53 & 2.97 \\
\hline Communicative evidentials & 0 & 0 & 0 \\
\hline Imperative mood & 0.81 & 0.50 & 0.89 \\
\hline
\end{tabular}


This table confirms the facts in figure two broken down into the different subcategories. Again, we can see how the speech delivered in the States widens the gap between this speech and the others as the number of frequency in every item differs greatly from the others. A closer view deserves the following comments:

- Epistemic stances. Roughly speaking, the pronoun mostly used is "I" as the speaker reflects his attitude towards the evidential, but it is interesting to notice how in the speech in Ghana the subject is not "I", as would be expected, but "America" or "foreign assistance" with the purpose of showing not a personal interest towards the country but that of the States.

Epistemic modality. We see in table one that high epistemic modality is remarkable in the three speeches, France's being the highest (13,40/1000). Examples in this speech like "we cannot fail", or "we must seek the solutions to the challenges of this young century" reflect the speaker's desirability about the proposition. On the contrary, in the USA text we find very few examples of epistemic modality. Clearly, the purpose is different: in France he wants to carry out actions in common and in the USA's speech he wants to clarify his position towards a topic.

Communicative evidentials. As we can see in the table, the expression of selfreference is higher in Ghana's speech and the lowest in France's. "I am speaking to you", "I am particularly speaking to the young people all across Africa" are some examples. On the contrary, in France he avoids using that self-recognition as an individual in the task to be performed. Added to this, in the USA text the use of "we" instead of "I" is widespread, expressing the feeling that his experiences have been undergone by every Afro-American not only himself with some exceptions like "I have already condemned, in unequivocal terms, the statements that Reverend Wright..."; "I confess that If all that I knew of R.W. were the snippets of those sermons...". In this last example the use of a verb related to religious matters cannot be considered a coincidence. But, in general terms, it is not a matter of personal opinion but of given facts. Furthermore, in the expression "you strongly disagreed" he means the community.

Experiential evidentials. The number of this category is quite similar in Ghana's and France's but lower in USA's. In Ghana's it has a positive bias in spite of the terrible problems the country faces. For example, at the beginning of the speech he said, "I do not see the countries and peoples of Africa as a world apart; I see Africa as a fundamental part of our interconnected world." The repetition of a structure using the core negative words and their positive is quite common. Even though other ways of signaling negation are possible, the use of the primary negative words gives a clear and straightforward message. In France he said "we find ourselves at a crossroads as well" or "we ensured our shared security" using once more the first person plural pronoun. So, even though the purpose and atmosphere is quite different in both countries the load of experiential evidentials is remarkable. Obama considered it necessary to have an active implication in both messages. On the other hand, the plural pronoun is also used in rare examples in America's by saying "we saw racial tensions bubble to the surface", or "we've heard the implication that my candidacy is somehow an exercise in 
affirmative action". Again, he tries to give facts rather than personal visions of the racial battle kept in the States during last decades.

Cognitive evidentials are not very common in Ghana though it is frequently used in the first part of the speech. Secondly, they are widely used in the speech in France to highlight the idea that the problem we face today was originated in the past. The structures "what we thought was important was for me to have an opportunity to not only speak with you", "we've known for a long time that the revolutions in communication" and "now, we take for granted a peace of a Europe that's united", "I know it can be tempting to turn inward, and I understand how many people and nations have been left behind by the global economy" are some examples in this speech with the purpose of reminding the historical reasons that have led to these military ties.

- Effective stances. The number of examples in the USA text is very low. Here Obama prefers the use of the passive voice or different subjects to bias the personal implication or simply deliver the information as factual.

Deontic modality. The speech delivered in France contains the highest number of examples and the American speech, the lowest. As deontic modality is concerned with necessity as obligation ("must") or possibility as some form of enablement ("may") this finding is not strange. Expressions like "we must forge", "we must not erect" or "we should all be proud" are spread throughout the whole text due to the need for unity during difficult times.

Volitive modality. In this case, the speech delivered in Ghana is the text with the highest number of examples. Modals that express high expectations and personal wish about future events are widely used in this text. Unequivocal sentences like "that will be a commitment of my administration", "we will carry forward the fight against HIV/AIDS" or "we will invest in public health systems" are some of the examples not found so clear-cut in the other speeches. In France, for example, the sentences "we will provide new markets, we will drive the growth of the future" are more vague.

Participant internal and external possibility. The speeches delivered in France and Ghana are the texts with the higher number of examples. Due to the characteristics of the speech delivered in the USA, it is fairly understandable to find an absence of examples as this speech is much more expositive than the others. In France the use of the modal "could" is common: "the theft of nuclear weapons could lead to the extermination of any city", "discoveries that could help us lead richer and fuller lives" but in Ghana "this is a responsibility that can only be met by Africans" or "if police can be bought off by drug traffickers" the modal "can" is used because even though not always the message is nice the personal responsibility is absent.

Participant internal and external necessity. This element is not much used in any of the speeches. In the USA example the modal "need" is repeated several times as in the example "we do not need to recite here the history of racial injustice in this country".

Attitudinal experience. I have hardly found any examples of attitudinal expressions in the speech delivered in America while there are ten in each of the others. "We applaud France's decision to expand and deepen its participation in NATO", "we support a strong European defense", "we welcome Croatia and Albania into the fold" 
are some examples found in the speech delivered in France, trying to be supportive and encouraging.

Communicative evidentials. No examples have been found.

Imperative mood. The examples found in the different texts are not relevant but in France, for instance, the imperative verb "let" is used: "let us resolve that when future generations look back on ours", "let us meet that responsibility together" softening the commanding bias.

Focusing now on the second purpose of this paper, if we omit the results extracted from the USA text and consider only the other two cases, null hypothesis should be accepted as the Chi square is below 0,05 . That is, the expectations created by these texts are fulfilled in the analysis. Interestingly, both texts have different intentions (the speech in France was to demand support for a war while in Ghana there was an offer of help if some rules were accepted) but the use of stance markers can be considered as predictable. This is due to several reasons:

1. Both of them belong to political speeches with their implications

2. They were delivered in foreign countries in the same year

3. They also belong to a long trip made as a presentation of his presidency. So they have a common purpose.

But, as said above, the speech delivered in the States breaks with this tendency.

\section{Conclusions}

The first purpose of the paper was to compare three speeches delivered in the time span of two years: the first in the USA before being elected President and the other two abroad as recently elected President of the United States. We have seen in the discussion of the findings that the American speech rejects the characteristics found in the others. This represented the turning point in the campaign but the fact of not having been elected yet and that the purpose is not to make promises makes it have different characteristics. On the other hand, in Ghana the self-reference, volitive and attitudinal elements are high, added to the participation internal-external possibility; that is, it is full of promises. In France, self-reference is lower but deontic modality and the necessity of carrying out actions in common permeate throughout all the speech.

Taking the three speeches individually, the USA epistemic stances double the number of effective stances, while the frequency of both data is quite low. The low frequency of both types of stances in the text considered "more personal" is also quite remarkable. Contrary to what we might have expected, Obama wanted to put aside his personal feelings and focus on the historical facts of the issue from an objective position.

In contrast, the speech delivered in Ghana contains the highest number of stances, epistemic and effective, in a fairly balanced number. Here, as the already elected President of the United States, he did not hesitate in demonstrating his positive attitude towards the country. Seemingly, in the text from France, despite being delivered in an 
uncomfortable environment, the number of epistemic stances is even higher than in the previous example and the effective, quite similar. In a way, we could conclude that the President felt confident and relaxed in these venues compared with his feeling in the States before being elected.

Next, patterns not being varied they are repetitive. As the sample is composed of oral speeches, repetition of the same structure is a fairly common resource in this type of discourse and in the author of our study. Every message is repeated more than once so the stance, even using a different pattern, is commonly repeated. This explains the high number in some of the types and the almost null use of others. As a consequence, the richness of the speeches does not lie in the combination of those stances, but rather in the vocabulary and images used to discuss the messages. These images are partly presented through familiar anecdotes.

On the other hand, we have seen above the number of times every stance marker is repeated. In these facts we can see how null hypothesis is rejected and so, random hypothesis must be accepted while, interestingly, this is due to the low number of examples that the USA text has in contrast with the other two. This means that even if the study had been done with only the two foreign speeches, the result would have been completely different. The reasons why the USA text does not fit with the study may include the following:

1. Obama had not been elected President yet

2. It was a speech delivered in the States, where he would be elected President of the United States

3. The intention was to clarify and not to demand, as in the other examples

This study deserves a mention apart for the communicative evidentials. As we said above, they imply the self-reference of the author himself. And it is remarkable how the personal implication in texts is almost absent. That is, President expresses his wish to the performing of some actions without a personal implication. This break between what the States wish and what he as an individual would wish is outstanding. By saying "I have said" or "I have expressed" there is not an affective implication as it would be "I urged to do". This balance is quite measured in all the speeches but, as it would be expected, in the epistemic sample in Ghana he uses them more often than in France, for instance. An interesting conclusion arises from this detection: the attitude and stancetaking in the USA text cannot be considered spontaneous but well studied, much more so than in the other two cases.

\section{Acknowledgments}

I would like to thank Ph.D. Mathematician Juan M. Hernández-Guerra for his wise and illuminating comments on the method employed and the conclusions carried out. I have been very fortunate to count on his support and patience. 


\section{References}

Primary sources

Obama, Barack H. (2008): A more Perfect Union. Huffington Post. http://www.huffingtonpost.com/2008/03/18/obama-race-speech-read-th_n_92077.html Accessed July, 302013.

Obama, Barack H. (2009): Obama Ghana Speech. Huffington Post. http://www.huffingtonpost.com/2009/07/11/obama-ghana-speech-full-t_n_230009.html Accessed July, 302013.

Obama, Barack H. (2009): Remarks by President Obama at Strasbourg Town Hall. The White House. http://www.whitehouse.gov/the-press-office/remarks-president-obama-strasbourgtown-hall Accessed July, 302013.

Secondary sources

Alonso-Almeida, Francisco \& Margarita Melé-Marrero (2014): "Stancetaking in seventeenth century prefaces on obstetrics". Journal of Historical Pragmatics, 15 (1): 1-35.

Biber, Douglas et al. (2000): Longman Grammar of Spoken and Written English Essex: Longman.

Cavanaugh, Jillian R. (2012): "Entering into politics: Interdiscursivity, register, stance, and vernacular in northern Italy". Language in Society, 41: 73-95.

Durant, Alessandro (1990): "Politics and grammar: agency in Samoan political discourse". American Ethnologist, 17: 646-666.

Gastil John (1992): "Undemocratic Discourse: A Review of Theory and Research on Political Discourse". Discourse and Society, 3 (4): 469-500.

Hernández-Guerra, Conchi (2011): "Rhetorical and Metatextual Features in Political Discourse: The Case Of Obama's Speech On Race”. Elia, 11: 119-146.

Hernández-Guerra, Conchi (2012): "Textual, Intertextual and Rhetorical Features in Political Discourse: The Case of President Obama in Europe". RLyLA, 8: 59-75

Key, James P. (1997): Chi Square

http://www.okstate.edu/ag/agedcm4h/academic/aged5980a/5980/newpage28.htm. Accessed $26 / 07 / 2013$

Langacker, Ronald W. (2007): "Control and the mind/body duality: Knowing vs. effecting". Applications of Cognitive Linguistics, 14: 165.

Marín-Arrese, Juana. M. (2009): "Effective vs. epistemic stance, and subjectivity/ Intersubjectivity in Political discourse: a case study". In Anastasios Tsangalidis and Roberta Fachinetti, eds., Studies of English Modality. In Honour of Frank R. Palmer. Berlin: Peter Lang, 23-52.

Palmer, Frank (1987): Modality and the English Modals. London: Longman. von Wright, Georg H. (1951): An Essay in Modal Logic. London: Longman.

Zupnik, Yael-Janette (1994): "A pragmatic analysis of the use of person deixis in political discourse”. Journal of Pragmatics, 21(4): 339-383. 